\title{
ECONOMIES OF SCALE AND SCOPE IN MULTI-UTILITIES *
}

\author{
Mehdi Farsi, Aurelio Fetz, Massimo Filippini \\ Department of Management, Technology and Economics, ETH Zurich \\ Zurichbergstr. 18, CH-8032 Zurich, Switzerland \\ Tel. +41-44-632 06 50, Fax. +41-44-632 1050 \\ and \\ Department of Economics, University of Lugano \\ mfarsi@ethz.ch,afetz@ethz.ch,.mfilippini@ethz.ch
}

\begin{abstract}
This paper explores the economies of scale and scope in the electricity, gas and water utilities. These issues have a crucial importance in the actual policy debates about unbundling the integrated utilities into separate entities, a policy which has often been supported by the ongoing reforms in the deregulation of network industries. This paper argues that the potential improvements in efficiency through unbundling should be assessed against the loss of scope economies. Several econometric specifications including a random-coefficient model are used to estimate a cost function for a sample of utilities distributing electricity, gas and/or water to the Swiss population. The estimates of scale and scope economies are compared across different models and the effect of heterogeneity among companies are explored. While indicating considerable scope and scale economies overall, the results suggest a significant variation in scope economies across companies due to unobserved heterogeneity.
\end{abstract}

JEL Classification: C33, D24, L11, L25, L94, L95

\footnotetext{
* This study has benefited from the financial support of the Swiss National Science Foundation through research grant 100012-108288 and also that of the State Secretariat for Economic Affairs (SECO), which is gratefully acknowledged. The authors also wish to thank Adonis Yatchew and two anonymous reviewers for their very helpful suggestions.
} 


\section{Introduction}

In Switzerland's energy sector, there is a certain tendency that local utility companies operate in both electricity and gas distribution as well as in the provision of water. Generally, this horizontal integration strategy allows the local multiutility companies to save on costs by exploiting the economies of scope and to provide customers with an integrated set of services. As pointed out by Baumol, Panzar et al. (1982), economies of scope can result from sharing or joint utilization of inputs such as labor and capital. The distribution companies use similar equipment such as wires, overhead line and similar skills such as those required for network operation and maintenance. Synergies also exist in advertising and billing activities. Another source of cost savings is due to economies of 'massed reserves' (Waldman and Jensen (2001)). Multi-utility companies can make use of the same reserve capacity for maintenance and emergency repair activities.

During the last two decades the introduction of high levels of competition in the electricity and gas sectors of several EU-member countries has raised the general question of the necessity of unbundling services of utility companies. The regulatory reforms have been toward a separation of activities in the form of functional, legal or ownership unbundling, which are often believed to lower entry barriers and boost competition. However, the importance of the potential synergies through 'horizontal' integration has been recognized in the recent European regulatory recommendations (cf. DG Energy \& Transport (2004)). An effective policy for unbundling multi-utilities, requires a reliable assessment of the scope economies and their variation with the company‘s size and other characteristics.

Despite its policy importance, there are only a few studies that have studied the issue of scope economies in multi-utilities. In general, these studies suggest that 
the scope economies are considerable at least for relatively small companies. However, the evidence as to the extent and statistical significance of the scope economies is rather mixed. A major difficulty in estimating scope and scale economies is the fact that utilities operate with different networks with various environmental and technical characteristics, which might induce various levels of synergies across different services. Many of these characteristics are not observed or difficult to measure. Such omitted variables could bias the estimation results. Moreover, the differences among companies could be beyond their variation in output and size. In fact, the strong heterogeneity among utilities operating in such different environments, suggests that a cost function with constant coefficients might be inadequate for a reliable analysis of scope economies.

Given that such network characteristics can be considered more or less constant over time, panel data can be used to account at least partially, for such heterogeneity and perhaps assess the potential biases. However, to our knowledge none of the previous studies in this field has used the advantages of panel data models to account for heterogeneity among companies.

Benefiting from a data set from 87 companies over a nine-year period, this paper applies two panel data models, a GLS model with random intercept and a random coefficient model, to estimate the scope and scale economies for individual firms. The variation across individual companies has been studied regarding both observed and unobserved heterogeneity. The results suggest significant scope and scale economies at most output levels and regardless of the variation in observed characteristics. The analysis also highlights the effect of unobserved heterogeneity across companies, suggesting that sophisticated econometric specifications such as random coefficients may be superior for analyzing the potential variation in scope and scale economies beyond the observed characteristics such as output patterns and customer density. 
The rest of the paper is organized as follows. Section 2 presents the background along with a brief review of previous literature. The model specification and methods are presented in Section 3. Section 4 describes the data and Section 5 presents the regression results. The definition of scale and scope economies and their estimates are discussed in Section 6. The paper ends with a summary of main results and policy conclusions.

\section{Background}

The ongoing regulatory reforms in the energy sector in many countries have adopted measures toward unbundling public utilities into separate operations. The traditional models based on vertical integration in single sectors are often rejected. Especially, in the electricity sector the vertically integrated companies are generally required to unbundle the production, transmission and distribution functions. For instance, the directive 2003/54/EC of the European Parliament and of the EU Council of 26 June 2003 requires a legal and functional unbundling of the utilities operating in a single sector.

As opposed to 'vertical' unbundling that is generally being promoted by the ongoing reforms, the 'horizontal' unbundling of multi-utilities has remained an open question with less clear-cut recommendations. The unbinding guidelines released by the EU Directorate-General of Energy and Transport (DG Energy \& Transport (2004)) state that the extent of management separation between activities related to different sectors "can only be decided on a case by case basis". Further it is highlighted that a clear answer to this unbundling question requires a "balanced assessment of, on the one hand, the need for independence and, on the other hand, the interest of multi-utility operators to look for possible synergies.” While allowing certain flexibility in unbundling multi-utilities, this note 
requires the policy makers to assess the extent of the economies of scope before taking policy decisions.

According the EU policy directive all the utilities with fewer than 100,000 customers can be exempt from any functional unbundling requirement. The distinction of small and large companies is based on the relative insignificance of scope economies in large companies that exploit scale economies. Such discriminative policies allow small companies to benefit from other synergies than scale economies. Since Switzerland is among the European countries with a large number of small companies in its energy sector, it provides a policyrelevant context for exploring the economies of scope. Moreover, although Switzerland does not belong to the European Union, the Swiss unbundling requirements upcoming in the near future, will probably reflect those discussed in the European directives. This study can provide the Swiss policy-makers with some insight concerning the effectiveness of similar regulatory measures in Switzerland.

Unbundling the services into separate functions allows a greater efficiency through stronger and more transparent competition that can be separately introduced in electricity, gas and water sectors. However, the implementation of the unbundling requirements will reduce the possibility of exploiting the economies of scope. The analysis of scope economies and its assessment across different companies can have important policy implications for the actual policy debates on the regulatory reforms in the Swiss gas and electricity sectors. Therefore, it is relevant for the Swiss federal authorities to identify if and to what extent multiutility companies are able to use the scope and scale economies to reduce their costs in comparison to a group of single-utility companies. This question is in line with the issue of multiproduct natural monopoly raised by Baumol, Panzar et al. (1982), which has been applied to local public services. In the presence of 
economies of scope a multiproduct firm is more economical than separate specialized firms. As first identified by Mayo (1984a), such economies are especially significant in relatively small companies. Therefore, the choice to exempt small and medium-size companies from the unbundling requirements could be sustained by economic arguments.

In the literature there are only a few studies on the economies of scope in multiutilities: Mayo (1984a), Chappell and Wilder (1986) and Sing (1987) in electricity and gas distribution, and Fraquelli, Piacenza et al. (2004) and Piacenza and Vannoni (2004) in electricity, gas and water sectors. Mayo (1984a) and Chappell and Wilder (1986) estimate a quadratic cost function for two cross sectional data sets from the US electricity and gas distribution sectors. Mayo (1984a) reports scope economies only for small companies, whereas Chappell and Wilder (1986) conclude significant scope economies over most of output ranges. Sing (1987), also using a cross-sectional data set including electricity and gas distributors, estimates a generalized translog cost function with a BoxCox transformation for outputs. In addition to the factor prices of labor, capital and fuel, he includes the customer density as an output characteristic. While reporting diseconomies of scope for the sample mean Sing (1987) finds scope synergies for certain output combinations, without any clear pattern with respect to the outputs magnitude.

The relatively recent papers by Fraquelli, Piacenza et al. (2004) and Piacenza and Vannoni (2004) use data from 90 Italian electricity, gas and water distributors over 3 years. However the data is pooled across the years and no panel data models are applied. They compare different functional forms such as the translog cost function with a small value transformation, the generalized translog, the separable quadratic and the composite cost function introduced by Pulley and 
Braunstein (1992). They conclude that economies of scope exist but their statistical significance can only be asserted over small outputs.

A summary of the above studies and their main results is presented in Table 1.

As we can see, panel data has hardly been utilized to date. The short panels used

in the recent studies by Fraquelli, Piacenza et al. (2004) and Piacenza and Vannoni (2004) probably have not allowed the authors to account for unobserved heterogeneity and correlation in the error terms. Another interesting study is Yatchew (2000) who applied a semi-parametric model to a 3-year panel data set of Canadian electricity distributors. Focusing on scale economies that author uses an additional dummy variable to account for the economies of scope gained by joint distribution of water and electricity.

Table 1: Summary of previous empirical studies of multi-utilities

\begin{tabular}{|c|c|c|c|c|c|}
\hline & Mayo (1984a) & $\begin{array}{l}\text { Chappell and } \\
\text { Wilder (1986) }\end{array}$ & Sing (1987) & $\begin{array}{l}\text { Fraquelli, } \\
\text { Piacenza et al. } \\
\text { (2004) }\end{array}$ & $\begin{array}{l}\text { Piacenza and } \\
\text { Vannoni } \\
(2004)\end{array}$ \\
\hline Data & $\begin{array}{l}\text { Cross-section } \\
(1979, \text { US })\end{array}$ & $\begin{array}{l}\text { Cross-section } \\
\text { 1981, US) }\end{array}$ & $\begin{array}{l}\text { Cross-section } \\
1981 \text {, US) }\end{array}$ & $\begin{array}{l}\text { Pooled } \\
\text { (1994-96, Italy) }\end{array}$ & $\begin{array}{l}\text { Pooled } \\
\text { (1994-96, Italy) }\end{array}$ \\
\hline $\begin{array}{l}\text { Functional } \\
\text { form }\end{array}$ & $\begin{array}{l}\text { Quadratic and } \\
\text { flexible fixed } \\
\text { costs quadratic }\end{array}$ & Quadratic & $\begin{array}{l}\text { Generalized } \\
\text { translog }\end{array}$ & $\begin{array}{l}\text { Translog, general- } \\
\text { ized translog, } \\
\text { separable quad- } \\
\text { ratic and compos- } \\
\text { ite }\end{array}$ & $\begin{array}{l}\text { Translog, } \\
\text { generalized } \\
\text { translog, } \\
\text { separable } \\
\text { quadratic, } \\
\text { composite and } \\
\text { general form } \\
\text { (Pulley and } \\
\text { Braunstein } \\
(1992) \text { ) }\end{array}$ \\
\hline $\begin{array}{l}\text { Estimation } \\
\text { method }\end{array}$ & OLS & OLS & SUR & NLSUR & NLSUR \\
\hline Outputs & $\begin{array}{l}\text { Electricity and } \\
\text { gas distribution }\end{array}$ & $\begin{array}{l}\text { Electricity and } \\
\text { gas distribution }\end{array}$ & $\begin{array}{l}\text { Electricity and gas } \\
\text { distribution }\end{array}$ & $\begin{array}{l}\text { Electricity, gas } \\
\text { and water distribu- } \\
\text { tion }\end{array}$ & $\begin{array}{l}\text { Electricity, gas } \\
\text { and water } \\
\text { distribution }\end{array}$ \\
\hline Factor prices & Labor, fuel & - & Labor, capital, fuel & Labor, other inputs & $\begin{array}{l}\text { Labor, other } \\
\text { inputs }\end{array}$ \\
\hline $\begin{array}{l}\text { Other } \\
\text { factors }\end{array}$ & - & - & Customer density & - & - \\
\hline $\begin{array}{l}\text { Economies } \\
\text { of scope }\end{array}$ & $\begin{array}{l}\text { Exist only for } \\
\text { small compa- } \\
\text { nies (+0.77\%), } \\
\text { for large } \\
\text { companies } \\
\text { diseconomies } \\
\text { (up to }-11.7 \% \text { ) }\end{array}$ & $\begin{array}{l}\text { Exist over most } \\
\text { of the output } \\
\text { ranges, }+12 \% \\
\text { for small, }-10 \% \\
\text { for largest } \\
\text { companies }\end{array}$ & $\begin{array}{l}\text { Output combina- } \\
\text { tions of both scope } \\
\text { economies and } \\
\text { diseconomies, no } \\
\text { economies of } \\
\text { scope for the mean } \\
\text { output (-7.2\%) }\end{array}$ & $\begin{array}{l}\text { Exist, but signifi- } \\
\text { cant only for } \\
\text { companies produc- } \\
\text { ing less than the } \\
\text { median output }\end{array}$ & $\begin{array}{l}\text { Exist with all } \\
\text { the models } \\
\text { except with the } \\
\text { translog cost } \\
\text { function. For } \\
\text { the median } \\
\text { output between } \\
16 \text { and } 64 \%\end{array}$ \\
\hline $\begin{array}{l}\text { Economies } \\
\text { of scale }\end{array}$ & $\begin{array}{l}\text { Product- } \\
\text { specific econo- } \\
\text { mies of scale } \\
\text { for gas over all } \\
\text { outputs, for } \\
\text { electricity only } \\
\text { for small } \\
\text { companies }\end{array}$ & $\begin{array}{l}\text { Global and } \\
\text { product- } \\
\text { specific } \\
\text { economies of } \\
\text { scale exist }\end{array}$ & $\begin{array}{l}\text { Product-specific } \\
\text { economies of scale } \\
\text { for electricity, } \\
\text { diseconomies for } \\
\text { gas }\end{array}$ & $\begin{array}{l}\text { Exist, but signifi- } \\
\text { cant only for } \\
\text { companies produc- } \\
\text { ing less than the } \\
\text { median output }\end{array}$ & $\begin{array}{l}\text { All the models } \\
\text { show econo- } \\
\text { mies of scale } \\
\text { except the } \\
\text { translog model }\end{array}$ \\
\hline
\end{tabular}


Given that the energy distribution companies operate in strongly heterogeneous environments, accounting for firm-specific unobserved factors might change the estimates of scope and scale economies. The moderately long panel data set used in this study allows the use of panel data models that can account for such heterogeneity and assess their effects on the estimations.

Before turning to the model it is worth noting that the Swiss energy sector is a fragmented market characterized by a strong heterogeneity across the 3,023 communities. With a total of 940 electricity utilities, 124 gas companies and 2,995 water distributors Switzerland's energy sector is characterized by its staggeringly large number of distributors with a prevalence of small and medium size companies throughout the 3,023 Swiss communities (cf. Dymek and Glaubitz (2003), VSG (2007) and Föllmi and Meister (2005)). Multi-utilities play an important role in all three sectors: The share of multiproduct utilities in the electricity and gas sectors is respectively about 35 and 75 percent of the total national consumption. With a roughly estimated share of 80 percent of the total national consumption, multi-utilities are also dominant in the water sector. ${ }^{1}$ In general multi-utilities tend to be active in all three sectors. The share of doubleoutput utilities is relatively low (limited to a few percentage points), especially in the gas sector.

\section{Model specification and estimation method}

The model specification is based on a cost function with three outputs (electricity, gas and water). The model also includes a measure of the characteristic of

\footnotetext{
${ }^{1}$ The numbers for electricity and gas are based on the data from 127 electricity distributors and 80 gas companies that respectively provide about $90 \%$ of electricity and gas consumption in Switzerland. The share in water distribution is estimated based on the available data from 95 companies that provide about 41 percent of the national water consumption.
} 
the service area and three sector-specific linear time trends capturing technological changes. Moreover, four input prices are also included in the model. As in Sing (1987) customer density is introduced as a service area characteristic. This variable should capture, at least partially, the impact on costs of the heterogeneity of the service area of the companies. In fact, differences in networks and environments influence the production process and, therefore, the costs. Of course, we are aware that the heterogeneity of the service area cannot be summarized into one single variable. Unfortunately, the information is not available for all network and environmental characteristics. Thus, many of these characteristics are omitted from the cost function specifications. As we see later these omitted factors are represented by firm-specific stochastic components in the adopted panel data econometric models.

If it is assumed that the firm minimizes cost and that the technology is convex, a total cost function can be written as:

$$
C=C\left(q^{(1)}, q^{(2)}, q^{(3)}, w^{(1)}, w^{(2)}, w^{(3)}, w^{(4)}, r, \tau^{(1)}, \tau^{(2)}, \tau^{(3)}\right)
$$

where $C$ represents total costs; $q^{(1)}, q^{(2)}$ and $q^{(3)}$ are respectively the distributed electricity, gas and water during the year, $w^{(1)}, w^{(2)}, w^{(3)}$ and $w^{(4)}$ are respectively the input factor prices for labor and capital services and the purchased electricity and gas; $r$ is the customer density measured by the number of customers divided by the size of the service area measured in square kilometers; and the sector-specific linear trends are represented by $\tau^{(1)}, \tau^{(2)}$ and $\tau^{(3)}$ respectively for electricity, gas and water sectors.

Following Baumol, Panzar et al. (1982) and Mayo (1984a) we use a quadratic cost function. This form has been considered as one of the most relevant options for estimating scope economies (Tovar, Jara-Diaz et al. (2007)). Unlike loga- 
rithmic forms, this functional form accommodates zero values for outputs thus, allows a straightforward identification of scope economies. Although logarithmic functions could be used with an arbitrary small value transformation for zero values, it has been shown that this approach could result in large errors in the estimation of scope economies (Pulley and Humphrey (1993)). As in our case, many output values for electricity, gas and water distribution are zero, such estimation errors may lead to misleading conclusions about scope economies.

The choice of the quadratic functional form has been also in close relationship with the econometric specification possibilities for the available panel data that will be described later. In fact, unlike other functional forms, the quadratic functional form can be easily estimated with panel data models. For instance, the application of panel data models (especially the random effects models) in nonlinear models such as Box-Cox or the composite model (Fraquelli, Piacenza et al. (2004), Mayo (1984b)) is not straightforward. Given the potential importance of the unobserved heterogeneity in the data we focused on the quadratic functional form that is readily adaptable to panel data models. Especially as the utilities operate in environments characterized by strong heterogeneity and given the fact that the integrated companies as well as specialized utilities are included in the data, the omitted variables could have an important effect that can be better accounted for in panel data models. By a similar argument we excluded the equation system approach with factor share equations as this approach cannot easily accommodate random effects specification.

One disadvantage of the quadratic form is that the linear homogeneity of the cost function in input prices cannot be imposed by parametric restrictions without compromising the flexibility of the functional form (Caves, Christensen et al. (1980)). A fairly common approach around this issue is the normalization of all monetary variables by one of the common factor prices referred to as nu- 
meraire price (see Farsi, Fetz et al. (2007), Featherstone and Moss (1994) and Jara-Diaz, Martinez-Budria et al. (2003)). However, depending on which input factor is chosen as the numeraire, the normalized model has non-unique solutions that might result in certain discrepancy across the estimates. ${ }^{2}$ Considering this drawback, we favored the non-normalized version of the model that has a greater flexibility as well as a better robustness. Especially in the context of this paper, in which the main focus is on the output coefficients that determine the economies of scope and scale, imposing the linear homogeneity restriction does not appear to provide any added value into the analysis. ${ }^{3}$

The adopted quadratic cost function using a random effects specification can be written as follows:

$$
\begin{aligned}
C_{i t}= & \alpha_{0}+\sum_{m}^{M} \alpha^{m} q_{i t}^{(m)}+\frac{1}{2} \sum_{m}^{M} \sum_{n}^{M} \alpha^{m n} q_{i t}^{(m)} q_{i t}^{(n)}+\sum_{p}^{p} \beta^{p} w_{i t}^{(p)} D_{i}^{(p)} \\
& +\alpha^{r} r_{i t}+\sum_{m}^{M} \gamma^{m} \tau_{t}^{(m)} D_{i}^{(m)}+u_{i}+\varepsilon_{i t}
\end{aligned}
$$

where superscripts $m$ and $p$ denote respectively, the number of products $(1,2,3)$ and the number of input factors $(1,2,3,4)$, and subscripts $i$ and $t$ denote respectively the company and year. The stochastic terms $u_{i}$ and $\varepsilon_{i t}$ represent respectively the firm-specific individual effects and the error term. The factor prices $w$ and the density variable $r$ are introduced in a linear way (following Mayo (1984a)). The dummy variables $D_{i}^{(p)}$ take one if the corresponding input factor

\footnotetext{
${ }^{2}$ Because of its additive form the obtained quadratic models are not equivalent. This is in contrast with multiplicative models such as translog in which normalization is perfectly invariant to the choice of the numeraire and equivalent to a single parametric restriction.
} 
has been used in the production. These dummies, relevant only for electricity and gas prices, allow to exclude the corresponding term if the company does not distribute electricity or gas (see Isaacs (2006) for this approach). The linear trends $\tau_{t}^{(m)}$ are specific to the sector as each one of the sector might be subject to a different technological progress. Similarly, dummy variables $D_{i}^{(m)}$ represent the cases in which the company distributes the corresponding product (electricity, gas and water). Finally $\alpha_{0}$ is the intercept. The alternative specification would be a flexible fixed cost model as in Mayo (1984a) and Panzar (1989), which includes several intercepts depending on the sector or the utility's output combination. We explored this possibility, but given that the estimated intercepts are not significantly different from each other, we favored the simpler model with a single intercept.

The quadratic form is a flexible functional form that can be considered as a second-order Taylor approximation of any arbitrary function around a local approximation point. In this paper following the commonly used approach in the literature (e.g. Jara-Diaz, Martinez-Budria et al. (2003)), the sample mean has been used as the approximation point. This normalization has been obtained by demeaning all the included explanatory variables (subtracting from their mean values). Therefore the intercept $\alpha_{0}$ captures the total costs of production at the sample mean.

\footnotetext{
${ }^{3}$ This has been confirmed by a supplementary analysis (available upon request) in which we have considered normalizing the costs and input prices by the labor price. The results suggest no significant change as far as the scope and scale economies are concerned.
} 
The above cost function has been specified as a random effect GLS model with: $u_{i} \sim$ iid $\left(0, \sigma_{u}^{2}\right) .{ }^{4}$ This model has a clear advantage over an alternative crosssectional model that pools the data across companies, thus simplifies the firmspecific effects in a constant intercept. Using individual effects $u_{i}$, the GLS model allows for certain variation among companies regarding the model's intercept, that as pointed out by Jara-Diaz, Martinez-Budria et al. (2003), has an important effect on the estimates of economies of scope. The main assumption is that the random effects $u_{i}$ are uncorrelated with the explanatory variables, a restriction that could be relaxed in a fixed-effects specification. ${ }^{5}$

However, the reliability of fixed-effects estimators depends on the extent of within-company variations that is, the variation of costs and outputs of given companies over time. As Cameron and Trivedi (2005) pointed out, the fixedeffects approach has an important weakness in that the coefficients of explanatory variables are "very imprecise" if the variable's variation over time is dominated by that across companies (between variation). ${ }^{6}$ The data used in this study show a relatively low within variation (variation over time) in some of the variables, especially, the ratios between the three outputs remain more or less constant within a given company. The extremely low variation in some of the vari-

\footnotetext{
${ }^{4}$ We have also estimated an alternative random effects model with AR1 serial correlation. The results (available upon request) do not show any significant difference between the corresponding coefficients.

${ }^{5}$ Such correlation might create 'heterogeneity bias' in the estimates (more on this later). The term 'heterogeneity bias' probably coined by Chamberlain (1982), has also been used for the bias due to ignoring variation of regression coefficients across individuals (e.g. Asteriou and Hall (2007)).

${ }^{6}$ Johnston and DiNardo (1997) also show that the 'attenuation' bias due to measurement errors is exacerbated in the fixed-effects models depending on the fraction of the within variation due to 'mismeasurement' especially when the explanatory variables are correlated across time. In our case it is plausible that the reporting errors have a contribution in the observed within variations.
} 
ables coupled with the presence of the second-order terms in the quadratic functional form also exacerbate the risk of multicollinearity, thus unreliable results. ${ }^{7}$

Moreover, the fixed-effects estimators are strongly conditioned upon the companies included in the sample, thus not convenient for boundary predictions at output bundles with zero values that are required for the estimation of scope economies. ${ }^{8}$ In fact the definition of the economies of scope relies on a comparison of the company's costs of producing all outputs with those of the same company with zero production in certain outputs. However, changes from positive output to zero output usually do not occur within a specific company. Therefore, the economies of scope can only be identified through the variations between a given company and other companies that are similar in all aspects but have little or zero production in those outputs. In the fixed-effect model such between variations are entirely captured by the company's individual effect, thus excluded from the cost function. Considering the above discussion, we excluded the fixed-effect model and focused on the random effects framework. We recognize however, the limitation of the adopted models concerning the assumption that omitted factors are uncorrelated with the explanatory variables.

In the random effects model the unobserved firm-specific heterogeneity is accounted for by individual effects. These factors might be correlated with the explanatory variables, in which case the estimations might be affected by 'het-

\footnotetext{
${ }^{7}$ Following a referee's suggestions we estimated several fixed-effects models. The results (available upon request) indicate that the estimates of the main output coefficients are quite sensitive to the included variables and occasionally counter-intuitive, suggesting that the within variation is not sufficient in order for the fixed-effects model to provide sensible results.
}

${ }^{8}$ As pointed out by Hsiao (2003), while the fixed-effects model is more appropriate for conditional predictions for individuals, the random effects is a better specification for unconditional (population- 
erogeneity bias.' One improvement over the GLS model in this respect could be obtained by including random coefficients for those explanatory variables. The variation of these coefficients should capture part of the correlation of the random intercept with the corresponding variables. Moreover, the unobserved firmspecific heterogeneity could also apply to marginal costs represented by the coefficients of the cost function. Therefore, we also estimate the cost function using a random coefficient (RC) model. ${ }^{9}$ In this model the three output coefficients, the intercept and the output characteristics are assumed to be random variables with a normal distribution across companies.

The quadratic cost function with the adopted random coefficient specification can be written as follows:

$$
\begin{aligned}
C_{i t}= & \alpha_{i}^{0}+\sum_{m}^{M} \alpha_{i}^{m} q_{i t}^{(m)}+\frac{1}{2} \sum_{m}^{M} \sum_{n}^{M} \alpha^{m n} q_{i t}^{(m)} q_{i t}^{(n)}+\sum_{p}^{P} \beta^{p} w_{i t}^{(p)} D_{i}^{(p)} \\
& +\alpha_{i}^{r} r_{i t}+\sum_{m}^{M} \gamma^{m} \tau_{t}^{(m)} D_{i}^{(m)}+\varepsilon_{i t}
\end{aligned}
$$

where $\alpha_{i}^{m} \sim N\left(\mu_{\alpha^{m}}, \sigma_{\alpha^{m}}^{2}\right)$, for $m=0,1,2,3$, and $\alpha_{i}^{r} \sim N\left(\mu_{\alpha^{r}}, \sigma_{\alpha^{r}}^{2}\right)$. Similar to the GLS model, all the explanatory variables are normalized to their sample means. The above random coefficient model has been estimated using a simulated maximum likelihood method. The firm-specific parameters are estimated for individual companies as their conditional expectation.

averaged) analysis provided that the random effects are uncorrelated with the explanatory variables. See also Cameron and Trivedi (2005) and Verbeek (2004) for a discussion of this issue.

${ }^{9}$ For a presentation of this model see Cameron and Trivedi (2005). See also Biørn, Lindquist et al. (2002) for an application of this model in the estimation the returns to scale among heterogeneous technologies. 
The random coefficient model described above provides a relatively rich specification that allows for interaction of unobserved factors such as network characteristics with outputs and customer density. However it has a shortcoming in that it imposes the normality assumption on the random intercept. Therefore the choice of the best model between the two depends on the trade-off between refining the econometric specification against the distribution restrictions. As we see later, as far as the estimates of the economies scale and scope are concerned, the results are not sensitive to this choice. Another important issue is that the specification of random coefficients can be extended to other variables. The benefits of such extensions should be assessed against the entailed numerical difficulties as well as the interpretation problems. ${ }^{10}$

\section{Data}

The unbalanced panel data set used for this analysis contains financial and technical information from 87 companies observed during the nine-year period between 1997 and 2005. The companies in the sample cover about $42 \%$ of total electricity, $67 \%$ of total gas and $22 \%$ of total water distribution in Switzerland. Among these companies, 33 are fully integrated and offer electricity, gas and water. 11 companies offer electricity and water, 3 companies distribute gas and water and 2 companies electricity and gas. The remaining companies are specialized companies from which 23 are active only in electricity distribution, 12 only in gas distribution and 3 only in water distribution. The presence of just a

\footnotetext{
${ }^{10}$ Following the suggestion of a referee we estimated several alternatives in which the input prices especially capital price have also random coefficients. The results (available upon request) indicate that adding random coefficients to the model can cause convergence problems and numerical instability, otherwise, counterintuitive results that are difficult to interpret. These problems could be explained by the relatively large number of explanatory variables in the model and the fairly limited number of companies included in the data.
} 
few number of specialized water distributors could be considered as a drawback for the estimation of economies of scope. However, this limitation should be considered together with the fact that in a fair number of companies in the sample, the distribution of gas and electricity constitutes a small fraction of the total output. $^{11}$

The data were collected from the companies’ annual reports containing financial and technical information. ${ }^{12}$ As pointed out by Kaserman and Mayo (1991), the degree of vertical integration can have an important impact on costs, thus affecting the estimates of economies of scope. The problem does not arise in gas and water sectors, in which companies have a uniform level of integration with the generation section (fully integrated in the case of water and completely separate in gas companies). In order to abstract from the effect of vertical integration in electricity distribution, companies with more than $10 \%$ self-generation of total electricity distribution were excluded.

The variables for the cost function specification were constructed as follows. Total costs $(C)$ are calculated as the total expenditures of the energy and water distribution firms in a given year. The outputs $q^{(m)}$ are measured by the total

\footnotetext{
${ }^{11}$ The number of these companies depends on the units used for measuring the various outputs. For instance, if we choose the units such that the sample median values will have the same order of magnitude (GWh for gas and electricity $10^{4}$ cubic meters for water output) there are 14 companies whose water output is more than two third of their total output.

${ }^{12}$ Information on the size of the firm's distribution area is from the "Arealstatistik 2002" from the Federal Statistical Office and from the "Preisüberwacher".
} 
quantity delivered to the customers. The measurement units are GWh for electricity and gas and million cubic meters for water. ${ }^{13}$

Input prices are defined as factor expenditures per factor unit. Labor price $\left(w^{(1)}\right)$ is defined as the ratio of annual labor costs to the total number of employees as full time equivalent. As data on full time equivalent was not available for 40 companies and taking the number of employees including part time workers would underestimate the labor price, a correction was done by taking the mean with the labor price of the companies within the same canton. Following Friedlaender and Chiang (1983), the capital price $\left(w^{(2)}\right)$ is calculated as residual cost (where residual cost is total cost minus labor and electricity and gas purchases) divided by the network length. ${ }^{14}$ For the multi-utilities, the prices were weighted by the share of the residual costs in each sector to the total residual costs in all sectors (see also Fraquelli, Piacenza et al. (2004) for this approach). The electricity and gas price is defined as the expenditures of purchasing the input factors divided by the amount purchased (in MWh).

Table 2 provides the sample's descriptive statistics. All the costs and prices are adjusted for inflation using consumer price index and are measured in year 2000 Swiss Francs (CHF). As can be seen in the table, the sample shows a considerable variation in all three outputs.

\footnotetext{
${ }^{13}$ The distributed gas is generally reported in energy units rather than volume units. Given that the gas distributors in Switzerland mainly use the same source of imported natural gas with a uniform quality, we do not expect that the change of measurement unit has any effect on the results.

${ }^{14}$ More precise measures of capital stock and expenditures can be obtained from a perpetual inventory approach. Unfortunately such inventory data was not available.
} 
Table 2: Descriptive statistics (622 observations)

\begin{tabular}{|c|c|c|c|c|c|c|}
\hline Variabl & & Unit & Min. & Median & Mean & Max. \\
\hline$C$ & Total cost & CHF Million & 1.52 & 35.7 & 79.0 & 611.8 \\
\hline$q^{(1)}$ & $\begin{array}{l}\text { Electricity } \\
\text { distribution }\end{array}$ & GWh & 0 & 115.4 & 405.9 & 6’177.0 \\
\hline$q^{(2)}$ & $\begin{array}{l}\text { Gas distribu- } \\
\text { tion }\end{array}$ & GWh & 0 & 78.8 & 363.8 & 6’665.0 \\
\hline$q^{(3)}$ & $\begin{array}{l}\text { Water distri- } \\
\text { bution }\end{array}$ & Million $\mathrm{m}^{3}$ & 0 & 1.1 & 3.4 & 62.6 \\
\hline$w^{(1)}$ & Labor price & $\begin{array}{l}\mathrm{CHF} / \mathrm{em}- \\
\text { ployee }\end{array}$ & $75 ’ 575$ & 103’610 & $\begin{array}{r}104 ' 86 \\
3\end{array}$ & $153 ’ 673$ \\
\hline$w^{(2)}$ & Capital price & $\mathrm{CHF} / \mathrm{km}$ & 8’165 & $26^{\prime} 421$ & 34’018 & $234^{\prime} 796$ \\
\hline$w^{(3)}$ & $\begin{array}{l}\text { Electricity } \\
\text { price }\end{array}$ & CHF/ MWh & 43.5 & 103.2 & 101.0 & 163.5 \\
\hline$w^{(4)}$ & Gas price & CHF/ MWh & 16.3 & 29.1 & 30.3 & 63.2 \\
\hline$r$ & Density & $\begin{array}{l}\text { Customers/ } \\
\mathrm{km}^{2}\end{array}$ & 2.3 & 230.1 & 348.0 & 3’619.3 \\
\hline
\end{tabular}

\section{Results}

The estimation results obtained from the GLS model are given in Table 3. These results show that the output and input price coefficients are highly significant and have the expected positive sign.

As expected, the effect of customer density (coefficient $\alpha^{r}$ ), is negative, showing that an increase in the customer density decreases costs. The coefficients of the linear trends suggest different technological progress across the three sectors. The results, while suggesting a cost decrease in the electricity networks, indicate a growth in operating costs in both gas and water sectors. These differences might also be related to the differences in the regulation systems for these sectors. It is interesting to note that although almost all public utilities are undergoing regulatory reforms, the electricity distributors have been subject to a relatively more advanced de-regulation process. ${ }^{15}$ However, the relative growth

\footnotetext{
${ }^{15}$ The first official attempt for the de-regulation of the Swiss electricity market dates back to 2002.
} 
of costs in gas and water networks might be related to the relatively higher age of these networks, thus a more accentuated need for new investments.

Another interesting observation is the considerable variation of the random intercept as reflected in the estimate of $\sigma_{u}$. The significant variation of the fixed costs across companies might be considered as a support for models with flexible fixed costs suggested by Mayo (1984a) and Panzar (1989). However, our additional estimations with a similar model but a varying intercept across different sectors suggest no statistically significant differences across sectors. This result combined with a relatively important variation in the random effects indicates that the variation in the fixed costs across companies might be mainly due to unobserved variations across companies. However, as we will see later from the random coefficient model's results the GLS model could overstate the variation of intercept because it assumes constant slopes for all companies. 
Table 3: Regression results (GLS model)

\begin{tabular}{|c|c|c|c|}
\hline & \multicolumn{3}{|c|}{ Quadratic cost function (RE GLS) } \\
\hline$\alpha^{1}$ (Electricity output) & $152 ' 698$ & $* *$ & (3'318) \\
\hline$\alpha^{2}$ (Gas output) & $42 ' 659$ & $* *$ & $\left(4^{\prime} 210\right)$ \\
\hline$\alpha^{3}$ (Water output) & 2'266'445 & $* *$ & $\left(504^{\prime} 478\right)$ \\
\hline$\alpha^{11}$ & -22.33 & $* *$ & $(1.33)$ \\
\hline$\alpha^{22}$ & 0.18 & & $(1.54)$ \\
\hline$\alpha^{33}$ & $-43 ' 314$ & $*$ & $\left(22^{\prime} 532\right)$ \\
\hline$\alpha^{12}$ & 21.27 & $* *$ & $(3.91)$ \\
\hline$\alpha^{13}$ & $-1^{\prime} 687$ & $* *$ & (366) \\
\hline$\alpha^{23}$ & -970.71 & $* *$ & (230.47) \\
\hline$\beta^{1}$ (Labor price) & 132.75 & $*$ & (75.77) \\
\hline$\beta^{2}$ (Capital price) & 139.85 & $* *$ & (33.78) \\
\hline$\beta^{3}$ (Electricity price) & $127 ' 777$ & $* *$ & $\left(52^{\prime} 794\right)$ \\
\hline$\beta^{4}$ (Gas price) & $562 ' 209$ & $* *$ & $\left(111^{\prime} 478\right)$ \\
\hline$\alpha^{r}$ (Customer density) & $-7 ' 207.54$ & $* *$ & $\left(2^{\prime} 973.91\right)$ \\
\hline$\gamma^{1}$ (Electricity sector) & $-2{ }^{\prime} 639 ' 987$ & $* *$ & $(331 ' 928)$ \\
\hline$\gamma^{2}$ (Gas sector) & 945 '850 & $* *$ & (390'922) \\
\hline$\gamma^{3}$ (Water sector) & 1'544'447 & $* *$ & $(461 ' 136)$ \\
\hline$\alpha^{0}$ & $90 ' 140$ '600 & $* *$ & $\left(1^{\prime} 926 ' 850\right)$ \\
\hline$\hat{\sigma}_{u}$ & $10^{\prime} 586 ' 724$ & & \\
\hline$\hat{\sigma}_{\varepsilon}$ & 9'411'338 & & \\
\hline
\end{tabular}

** and * indicate $5 \%$ and $10 \%$ significance level respectively. Standard errors are given in parenthe-

ses.

In the random coefficient model, it is assumed that the intercept and the firstorder coefficients of output and customer density vary across companies. The random coefficient model was estimated with the simulated likelihood method using quasi-random Halton draws. ${ }^{16}$

\footnotetext{
${ }^{16}$ The number of draws has been fixed to 1000 . The model was also estimated with several numbers of draws between 100 and 1'000. The results indicate that after 500 draws, the estimations become stable.
} 
Table 4 lists the regression results obtained from the random coefficient model. The first important observation is that the estimated coefficients are slightly (but mostly not significantly) different from those obtained from the GLS model. However, the estimated standard deviations of the random coefficients are all statistically significant for electricity and gas output as well as the customer density. This suggests that there is a significant variation in the output and density coefficients across companies. As for the intercept the standard deviation shows a considerably lower value than that obtained from the GLS model ( $\hat{\sigma}_{u}$ in Table 3), suggesting that ignoring the heterogeneity in slopes can result in an overestimation of the variations of the fixed costs across companies.

The random coefficient estimators can be used to estimate the conditional expectation of firm-specific coefficients. These estimates show that for the intercept and the output coefficients, all the coefficients are positive, while for the customer density coefficient, 13 companies (out of 87) have positive coefficients. This can be explained by the fact that as customer density increases, certain companies incur extra costs through congestion effects or some unobserved network characteristics. ${ }^{17}$ The estimates of the variances of the random effects in both models (Table 3 and Table 4) show that there is a considerable unobserved firm-specific heterogeneity. We will see later if and how ignoring this heterogeneity could affect the estimates of scale and scope economies.

\footnotetext{
${ }^{17}$ We explored the possibility that the congestion effect might be related to some observed variables by including a square term for customer density and accounting for the network location in ru-

$\mathrm{ral} / \mathrm{urban}$ areas. The results do not show statistical significant effect which could lead to any conclusive evidence in this regard.
} 
Table 4: Regression results (Random coefficient model)

\begin{tabular}{|c|c|c|c|c|c|}
\hline \multirow[b]{3}{*}{$\alpha^{1}$ (Electricity output) } & \multicolumn{5}{|c|}{ Quadratic cost function (RC) } \\
\hline & \multicolumn{3}{|c|}{ Mean } & \multicolumn{2}{|c|}{ Standard deviation } \\
\hline & $162 ' 889$ & $* *$ & $(1 ' 533)$ & $15^{\prime} 652^{* *}$ & $(524)$ \\
\hline$\alpha^{2}$ (Gas output) & 50'132 & $* *$ & $\left(1^{\prime} 639\right)$ & $14^{\prime} 921^{* *}$ & $(882)$ \\
\hline$\alpha^{3}$ (Water output) & 1'562'760 & $* *$ & $(184 ' 820)$ & 9'289 & $\left(48^{\prime} 903\right)$ \\
\hline$\alpha^{11}$ & -32.21 & ** & $(0.95)$ & & \\
\hline$\alpha^{22}$ & -0.63 & & $(0.539)$ & & \\
\hline$\alpha^{33}$ & $-12 ' 262$ & & $\left(8^{\prime} 684\right)$ & & \\
\hline$\alpha^{12}$ & 25.78 & & $(2.80)$ & & \\
\hline$\alpha^{13}$ & $-1^{\prime} 704$ & & $(154)$ & & \\
\hline$\alpha^{23}$ & -399.68 & $* *$ & $(150.02)$ & & \\
\hline$\beta^{1}$ (Labor price) & 126.56 & $* *$ & $(30.94)$ & & \\
\hline$\beta^{2}$ (Capital price) & 128.91 & $* *$ & $(15.97)$ & & \\
\hline$\beta^{3}$ (Electricity price) & 91'957 & $* *$ & $(23 ' 154)$ & & \\
\hline$\beta^{4}$ (Gas price) & $522 ' 290$ & $* *$ & $\left(64^{\prime} 763\right)$ & & \\
\hline$\alpha^{r}$ (Customer density) & $-3 ' 829.95$ & $* *$ & $(983.31)$ & $14^{\prime} 200.7^{* *}$ & $\left(1^{\prime} 157.4\right)$ \\
\hline$\gamma^{1}$ (Electricity sector) & $-2^{\prime} 488 ' 370$ & $* *$ & $(198 ' 250)$ & & \\
\hline$\gamma^{2}$ (Gas sector) & 916 '995 & $* *$ & $(424 ' 060)$ & & \\
\hline$\gamma^{3}$ (Water sector) & 1'323'520 & $* *$ & $\left(432^{\prime} 471\right)$ & & \\
\hline$\alpha^{0}$ & 93'564'700 & $* *$ & $\left(682^{\prime} 477\right)$ & $108 ' 524$ & $\left(355^{\prime} 020\right)$ \\
\hline
\end{tabular}

** and * indicate $5 \%$ and $10 \%$ significance level respectively. Standard errors are given in parentheses.

The estimation results presented in Table 3 and Table 4 can be used to compute the estimated of the economies of scale and scope. These results along with a formal description of the concepts will be presented in the following section. 


\section{Scale and Scope Economies}

Following Baumol, Panzar et al. (1982) the global economies of scale in a multioutput setting are defined as:

$$
S L=\frac{C(q)}{\sum_{m}^{M} q^{(m)} * \frac{\partial C}{\partial q^{(m)}}}
$$

where $q=\left(q^{(1)}, q^{(2)}, q^{(3)}\right)$ for $m=1$ (electricity), 2 (gas) and 3 (water). Global economies of scale describe the cost behavior due to proportional changes in the entire production. The returns to scale are increasing, constant or decreasing if the corresponding ratio $(S L)$ is greater, equal or less than one.

Economies of scope are present when costs can be reduced by joint production of multiple outputs. Following Baumol, Panzar et al. (1982) the degree of global economies of scope across three products is defined as the ratio of excess costs of separate production to the costs of joint production of all outputs:

$S C=\frac{C\left(q^{(1)}, 0,0\right)+C\left(0, q^{(2)}, 0\right)+C\left(0,0, q^{(3)}\right)-C(q)}{C(q)}$

A positive (negative) value for the above expression implies the existence of global economies (diseconomies) of scope.

Scope and scale economies are usually estimated using the deterministic part of the cost function at some representative outputs. In previous studies these representative outputs are generally obtained by setting the outputs at different points of their sample distribution such as median and other quartiles. As seen in Equation (5), a correct estimation of economies of scope relies on adequately predicting of costs at certain points that are at the sample boundary or completely out 
of the sample. The precision of such predictions depends on the econometric specification. As discussed earlier, a GLS model provides a relatively accurate out-of-sample prediction. The random-coefficient model has an additional advantage with respect to heterogeneity bias in the coefficients. The predictions required for estimating scope and scale economies in Equations (4) and (5), can also be conducted at the individual company level, using the individual estimates of company-specific random effects and coefficients. The individual company-level estimates can better represent the actual output patterns. The company-level cost predictions might however entail relatively large estimation errors. In this paper, we have used both approaches.

Using Equations (4) and (5) and the regression results, the values of scope and scale economies have been estimated for five hypothetical companies with representative output combinations. These companies are characterized by the $1^{\text {st }}$, $2^{\text {nd }}, 3^{\text {rd }}$ and $4^{\text {th }}$ quintiles and the sample median of the non-zero output values and customer density. A summary of these results is provided in Table 5. These results suggest the presence of scope and scale economies at most output levels. The estimates also show a well-behaved variation: as outputs increase (decrease) both scale and scope economies fall (rise).

Table 5: Point estimates of global economies of scope and scale

\begin{tabular}{|l|c|c|c|c|}
\hline & \multicolumn{2}{|c|}{ Economies of Scope } & \multicolumn{2}{c|}{ Economies of Scale } \\
\hline $\begin{array}{l}\text { Representa- } \\
\text { tive firm }\end{array}$ & GLS & RC & GLS & RC \\
\hline 1. Quintile & 0.37 & 0.27 & 1.24 & 1.17 \\
\hline 2. Quintile & 0.22 & 0.16 & 1.14 & 1.09 \\
\hline Median & 0.17 & 0.12 & 1.10 & 1.07 \\
\hline 3. Quintile & 0.11 & 0.07 & 1.07 & 1.04 \\
\hline 4. Quintile & 0.03 & -0.003 & 1.06 & 1.03 \\
\hline
\end{tabular}

The representative points are based on positive values of the three outputs as well as the customer density. Input prices and time trends are kept constant at their sample mean values. The random effects (and coefficients) are assumed to be at their mean values. 
Representative sample points such as output quintiles correspond to hypothetical productions that vary in overall scale and density as they represent a more or less similar ratio between all outputs. In this case the firms with "non-typical" mixtures of outputs and customer density would not be represented. In order to study the variation of scale and scope economies in the sample, based on the actual levels of production rather than hypothetical values, we computed the economies of scope and scale for each individual company. Note that the definitions of global economies of scope and scale as defined in equations (4) and (5) is directly applicable only to all-positive-output combinations. In order to extend the estimates to other companies we have chosen a hypothetical all-positive output for each one of these companies. While keeping the positive observed values, we replaced the zero values by a positive value constructed based on the company's overall scale relative to all the companies in the sample. For any given company the "overall scale factor" is defined as that company’s maximum output standardized by the mean value and standard deviation of that output observed in the sample. For any given company the hypothetical output of a given zero output is constructed by multiplying the company's overall scale factor by the sample mean value of that output.

An alternative method would be to limit the estimates to the companies with allpositive outputs. However, the fact that the fully integrated companies might be a selection of companies in that they exploit the economies of scope and might have a lower fixed costs, could distort the estimates of scope economies. ${ }^{18}$

Table 6 and Table 7 respectively provide a summary descriptive of the distribution of the estimates of the global economies of scope and scale across the com-

\footnotetext{
${ }^{18}$ We have also estimated these values for the 33 fully integrated companies. The results do not show much difference.
} 
panies included in the sample. The results obtained from both GLS and RC models are listed. The first and third columns provide the estimates obtained by ignoring the random effects, namely the means of the random coefficients are considered. In the second and fourth columns, the firm-specific random effects are included in the calculation of scale and scope economies. The input prices and the time trends have been set equal to their mean values over the entire sample. Both GLS and RC estimates suggest the existence of scope and scale economies across a major part of the sample. Looking across the numbers from both models indicate that more than 60 percent of the companies can exhibit economies of scope and at least 80 percent can benefit from economies of scale.

Table 6: Distribution of global economies of scope estimated for individual companies

\begin{tabular}{|l|c|c|c|c|}
\hline & GLS $^{\mathrm{a}}$ & $\mathrm{GLS}^{\mathrm{b}}$ & $\mathrm{RC}^{\mathrm{a}}$ & $\mathrm{RC}^{\mathrm{b}}$ \\
\hline 1. Quintile & 0.05 & -0.11 & -0.02 & -0.18 \\
\hline 2. Quintile & 0.09 & 0.05 & 0.05 & 0.02 \\
\hline Median & 0.14 & 0.15 & 0.10 & 0.04 \\
\hline 3. Quintile & 0.17 & 0.19 & 0.11 & 0.10 \\
\hline 4. Quintile & 0.25 & 0.33 & 0.18 & 0.29 \\
\hline
\end{tabular}

a) Individual random effects are not taken into account. ${ }^{\text {b) }}$ Individual firm-specific random effects are included in the computations. The values are estimated for all individual observations. Input prices and time trends are kept constant at their sample mean values.

Table 7: Distribution of global economies of scale estimated for individual companies

\begin{tabular}{|l|c|c|c|c|}
\hline & GLS $^{\mathrm{a}}$ & $\mathrm{GLS}^{\mathrm{b}}$ & $\mathrm{RC}^{\mathrm{a}}$ & $\mathrm{RC}^{\mathrm{b}}$ \\
\hline 1. Quintile & 1.08 & 0.97 & 1.04 & 1.00 \\
\hline 2. Quintile & 1.11 & 1.09 & 1.06 & 1.05 \\
\hline Median & 1.12 & 1.15 & 1.07 & 1.07 \\
\hline 3. Quintile & 1.13 & 1.19 & 1.08 & 1.09 \\
\hline 4. Quintile & 1.22 & 1.28 & 1.13 & 1.24 \\
\hline
\end{tabular}

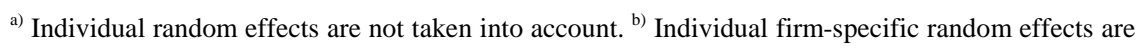
included in the computations. The values are estimated for all individual observations. Input prices and time trends are kept constant at their sample mean values.

Assuming that the larger companies have a lower potential of scale and scope economies (as suggested by Table 5), these results indicate that all small and 
moderate-sized utilities can benefit from significant savings through scale and scope economies. However, as seen in Table 6 and Table 7 the extent of these economies can vary depending on the adopted model and the approach used for accounting the estimated effects of unobserved factors. The first and third columns in both tables indicate that if the random effects are not considered in the computations, GLS and RC models provide a quite similar distribution of scale and scope economies across companies. However, a comparison of the first and third columns with the second and fourth ones respectively, suggests that including the individual random effects results in a wider range of variation in scale and scope economies. These results indicate that the economies of scope and scale could be influenced by unobserved factors beyond output and density. We could not find any conclusive pattern suggesting a one-sided bias because of ignoring such unobserved heterogeneity. The results suggest however that compared to GLS model, the RC model provides a lower overall estimate of both economies, as seen in slightly lower median values. This could be explained by the fact that the RC model gives a relatively lower weight to differences regarding fixed costs because part of these costs might be captured by random coefficients.

However, it should be noted that some of the observed variation in the above tables might be related to the relatively large estimation errors of the fixed costs across all models. Considering that the reliability of the individual estimates remains a contentious issue, we contend that the extreme values especially those of scope economies should be considered with caution. Overall these results suggest that a great majority of the companies can benefit from significant economies of scope and scale. Considering the median values these savings vary depending on the model, from 4 to 15 percent for scope economies and 7 to 15 percent for scale economies. Especially the small multi-utilities benefit from considerable scope economies that could reach 20 to 30 percent of total costs. 


\section{Conclusions}

Using a panel data set from the distribution utilities operating in water, gas and electricity sectors this paper has studied the economies of scope and scale in multi-output utilities. A random effect panel data (GLS) model and a randomcoefficient (RC) model have been used to explore the effect of unobserved heterogeneity across different networks. While the GLS model considers the unobserved heterogeneity as various cost shifts across companies, the RC model includes variations in marginal effects of outputs and customer density. Compared to cross-sectional model, the GLS specification provides a better control for omitted variables. The RC model provides an additional improvement regarding the potential heterogeneity bias in the coefficients' estimates.

This paper also shows that the computation of the economies of scope and scale can be extended to include the estimates of firm-specific individual effects, namely the conditional expectation of the random intercept and random coefficients. While admitting that such company-level estimates may entail relatively large estimation errors at the individual level, we assert that the overall results could represent a better picture of scope and scale economies based on actual levels of outputs and network characteristics rather than simplified hypothetical values.

From the results three general observations can be pointed out. First, the results confirm the existence of significant scope and scale economies in a majority of multi-utilities, which can be considered as suggestive evidence of natural monopoly in multi-utilities. This conclusion is confirmed across the two models and regardless of whether the individual firm-specific stochastic terms are included in the estimations. Secondly, considerable variation of the estimated values among individual companies suggests that the economies of scope and scale can depend on unobserved network characteristics as well as output patterns and 
customer density. Finally, the variations across the models indicate that the overall point estimates are not very sensitive to the specification of unobserved firm-specific factors.

The results of this paper show that even after accounting for unobserved heterogeneity, the scope economies exist in a majority of the multi-utilities, suggesting that additional costs could result from unbundling the multi-utility companies. In the actual situation many companies avoid these additional costs through scope economies. Especially for small companies the savings associated with scope economies are considerable.

In this study it is assumed that there is no functional separation between distribution and supply functions. While being possibly unrealistic in some EU countries, this assumption closely reflects Switzerland's actual situation and most probably, its future development. In fact, under the EU policy directive the utilities with fewer than 100,000 customers can be exempt from any functional unbundling requirement. As most of the distribution companies in Switzerland are relatively small with only a few companies having more than 100,000 customers, with a likely adoption of policies similar to those of EU, the distribution and supply are likely to remain integrated in the future. Therefore, the results of this study are especially relevant for the context of Switzerland as well as in many similar cases in other countries.

\section{References}

Asteriou, D. and S. G. Hall (2007). Applied econometrics: A modern approach. New York: Palgrave Macmillan.

Baumol, W. J., J. C. Panzar and R. D. Willig (1982). Contestable Markets and the Theory of Industry Structure. New York: Hartcourt Brace Jovanovich.

Biørn, E., K.-G. Lindquist and T. Skjerpen (2002). "Heterogeneity in Returns to Scale: A Random Coefficient Analysis with Unbalanced Panel Data." Journal of Productivity Analysis 18(1): 39-57. 
Cameron, A. C. and P. K. Trivedi (2005). Microeconometrics Methods and Applications. Cambridge: Cambridge University Press.

Caves, D. W., L. R. Christensen and M. W. Tretheway (1980). "Flexible Cost Functions for Multiproduct Firms." Review of Economics and Statistics 62(3): 477-81.

Chamberlain, G. (1982). "Multivariate Regression Models for Panel Data." Journal of Econometrics 18(1): 5-46.

Chappell, H. W. and R. P. Wilder (1986). "Multiproduct Monopoly, Regulation, and Firm Costs: Comment." Southern Economic Journal 52(4): 1168-74.

DG Energy \& Transport (2004). Note of DG Energy \& Transport on the Directives 2003/54/EC and 2003/55/EC on the internal Market in Electricity and Natural Gas, The Unbundling Regime, Brussels.

Dymek, B. and D. Glaubitz (2003). "Rütteln am eidgenössischen Tor." Energie \& Management 19: 4-5.

Farsi, M., A. Fetz and M. Filippini (2007). "Economies of scale and scope in local public transportation." Journal of Transport Economics and Policy forthcoming.

Featherstone, A. M. and C. B. Moss (1994). "Measuring Economies of Scale and Scope in Agricultural Banking." American Journal of Agricultural Economics 76(3): 655-61.

Föllmi, R. and U. Meister (2005). "Product-Market Competition in the Water Industry: Voluntary Non-discriminatory Pricing." Journal of Industry, Competition and Trade 5(2): 115-35.

Fraquelli, G., M. Piacenza and D. Vannoni (2004). "Scope and Scale Economies in Multi-Utilities: Evidence from Gas, Water and Electricity Combinations." Applied Economics 36(18): 2045-57.

Friedlaender, A. F. and W. Chiang (1983). "Productivity Growth in the Regulated Trucking Industry." Research in Transportation and Economics 1: 149-84.

Hsiao, C. (2003). Analysis of panel data. Cambridge: Cambridge University Press.

Isaacs, J. P. (2006). Determining the Regulatory Impact on Vertical Economies in the Electric Utility Industry, Fourth Annual International Industrial Organization Conference, Boston, Massachusetts.

Jara-Diaz, S. R., E. Martinez-Budria and F. J. Ramos-Real (2003). "Adapting Productivity Theory to the Quadratic Cost Function: An Application to the Spanish Electric Sector." Journal of Productivity Analysis 20(2): 213-29.

Johnston, J. and J. DiNardo (1997). Econometric methods. New York: McGraw-Hill.

Kaserman, D. L. and J. W. Mayo, (1991). "The measurement of Vertical economies and the Efficiency Structure of the Electricity Utility Industry" Journal of Industrial Economics 34 (5): 483-502.

Mayo, J. W. (1984a). "Multiproduct Monopoly, Regulation, and Firm Costs." Southern Economic Journal 51(1): 208-18.

Mayo, J. W. (1984b). "The Technological Determinants of the US Energy Industry Structure." Review of Statistics and Economics 66 (1): 51-58.

Panzar, J. C. (1989). Technological Determinants of Firm and Industry Structure, Handbook of Industrial Organization, R. Schmalensee and R. D. Willig, Amsterdam, Elsevier, Volume 1: 3-59. 
Piacenza, M. and D. Vannoni (2004). "Choosing among Alternative Cost Function Specifications: An Application to Italian Multi-utilities." Economics Letters 82(3): 415-22.

Pulley, L. B. and Y. M. Braunstein (1992). "A Composite Cost Function for Multiproduct Firms with an Application to Economies of Scope in Banking." Review of Economics and Statistics 74(2): 221-30.

Pulley, L. B. and D. B. Humphrey (1993). "The Role of Fixed Costs and Cost Complementarities in Determining Scope Economies and the Cost of Narrow Banking Proposals." Journal of Business 66(3): 437-62.

Sing, M. (1987). "Are combination Gas and Electric Utilities multiproduct natural Monopolies?" Review of Economics and Statistics 69(3): 392-8.

Tovar, B., S. R. Jara-Diaz and L. Trujillo (2007). "Econometric Estimation of Scale and Scope Economies Within the Port Sector: A Review." Maritime Policy \& Management 34(3): 203-23.

Verbeek, M. (2004). A guide to modern econometrics. Chichester: Wiley.

VSG (2007). Erdgas - Daten und Fakten, Tabellen und Grafiken 2006/07, Verband der Schweizerischen Gasindustrie (VSG), Zürich.

Waldman, D. E. and E. J. Jensen (2001). Industrial organization theory and practice. Boston: Addison-Wesley.

Yatchew, A. (2000). "Scale Economies in Electricity Distribution: A Semiparametric Analysis." Journal of Applied Econometrics 15(2): 187-210. 